\title{
Rapid anterior capsular contraction after phacoemulsification surgery in a patient with retinitis pigmentosa
}

This article was published in the following Dove Press journal:

Clinical Ophthalmology

3 May 2013

Number of times this article has been viewed

\author{
Tan Jin-Poi \\ Ismail Shatriah \\ Sonny Teo Khairy-Shamel \\ Embong Zunaina
}

Department of Ophthalmology, School of Medical Sciences, Universiti Sains Malaysia, Kubang Kerian, Malaysia
Correspondence: Ismail Shatriah Department of Ophthalmology, School of Medical Sciences, Universiti Sains Malaysia, 16150 Kubang Kerian, Kelantan, Malaysia

Tel +609767 6354

Fax +6097653370

Email shatriah@kck.usm.my

\begin{abstract}
A decrease in the anterior capsule opening after cataract surgery has been observed in eyes with weakened lens zonules. It commonly occurs in diabetes mellitus, uveitis, pseudoexfoliation syndrome, high myopia, and elderly patients. Herein, we report the case of a middle-aged man with advanced retinitis pigmentosa who developed a rapid contraction of the anterior capsule after an uneventful phacoemulsification surgery that resulted in severe visual loss during the early postoperative period.
\end{abstract}

Keywords: contraction of anterior capsule, early postoperative period, phacoemulsification surgery, retinitis pigmentosa

\section{Introduction}

Patients with retinitis pigmentosa are more predisposed to suffer from specific risk factors during cataract surgery. These include phototoxic retinal damage during the surgery, ${ }^{1-3}$ postoperative macular oedema, ${ }^{2,46}$ and posterior capsular opacification..$^{7-11}$ These conditions may result in poor visual acuity in patients with retinitis pigmentosa following the cataract surgery.

This case report highlights a rare occurrence of an aggressive anterior capsular contraction after an uneventful elective phacoemulsification surgery in a middle-aged man suffering from advanced retinitis pigmentosa. This resulted in significant visual loss during the early postoperative period.

\section{Case report}

A 49-year-old man presented with progressive, painless blurring of vision in both eyes. His best-corrected visual acuity was $6 / 18$ in both eyes. Slit-lamp biomicroscopic examination revealed posterior subcapsular cataract in both eyes. Fundus examination revealed the presence of a hyperpigmented bony spicule in the retina, attenuated arterioles, slightly pale optic discs, and dull foveal reflex in both eyes. Intraocular pressure was normal bilaterally. Humphrey 30-2 SITA fast visual field perimetry revealed concentric contraction with generalized depression of sensitivity in both eyes.

He was advised to undergo phacoemulsification cataract surgery and provided an explanation of guarded postoperative visual outcome. He underwent the phacoemulsification surgery and implantation of a CT-Asphina ${ }^{\circledR}$ 603P (Carl Zeiss Meditec, Jena, Germany) intraocular lens under sub-Tenon anesthesia in the right eye. The surgery was uneventful. His visual acuity was found to have improved to $6 / 15$ on the first postoperative day. 
However, the patient complained of significant, painless blurring of vision in the operated eye at 2-weeks post-surgery. On examination, his visual acuity was found to have reduced to counting fingers. The anterior capsule was markedly thickened, with a near total visual axis occlusion (Figure 1). The intraocular lens remained stable and enclosed centrally in the capsular bag. The fundus view was poor, and a B-scan of the right eye revealed clear vitreous and a flat retina.

A neodymium-doped yttrium aluminum garnet (Nd:YAG) laser anterior capsulotomy was performed under local anesthesia on the affected eye, and this resulted in improvement of the patient's visual acuity to $6 / 152$-weeks later. The visual axis was cleared (Figure 2). The patient was monitored at regular intervals following this.

Subsequently, he underwent an elective phacoemulsification surgery and AcrySof ${ }^{\circledR}$ IQ posterior chamber lens (Alcon, Hünenberg, Switzerland) implantation under sub-Tenon anesthesia in the other eye 6 months after surgery. The surgery was uneventful. A larger capsulorhexis of approximately $6 \mathrm{~mm}$ with multiple sites of radial incisions was performed intraoperatively. His postoperative visual acuity was 6/12. He was examined closely during the postoperative period and his visual axis remained unaffected.

The patient was last seen 2 months after the operation. His best-corrected visual acuity was $6 / 9$ in both eyes. Refraction result showed $+0.50 /-0.50 \times 170$ for the right eye and plano/ $-0.75 \times 110$ in the left eye. There was no sign of anterior capsular contraction in the left eye.

\section{Discussion}

According to our search of the PubMED and MEDLINE databases, there are few published case reports regarding

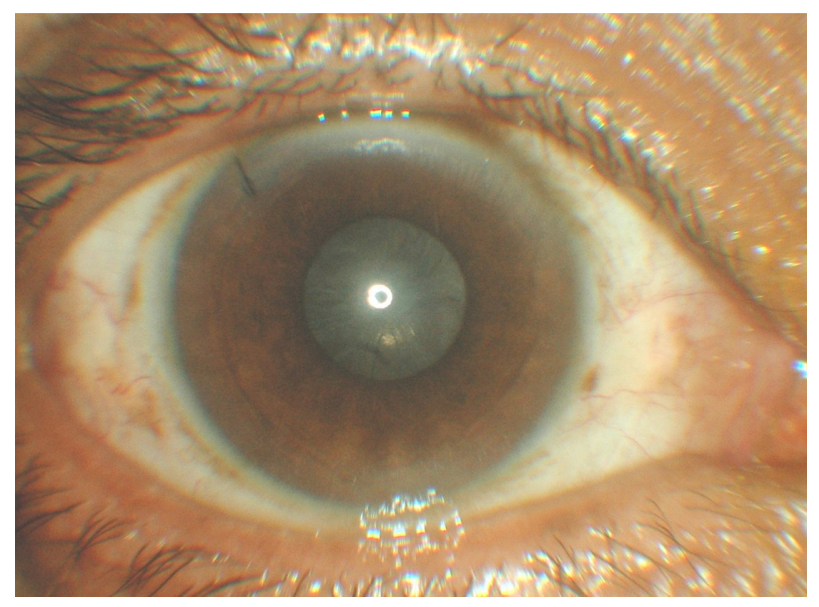

Figure I Anterior segment photograph showing anterior capsular contraction causing a near total occlusion of the visual axis.

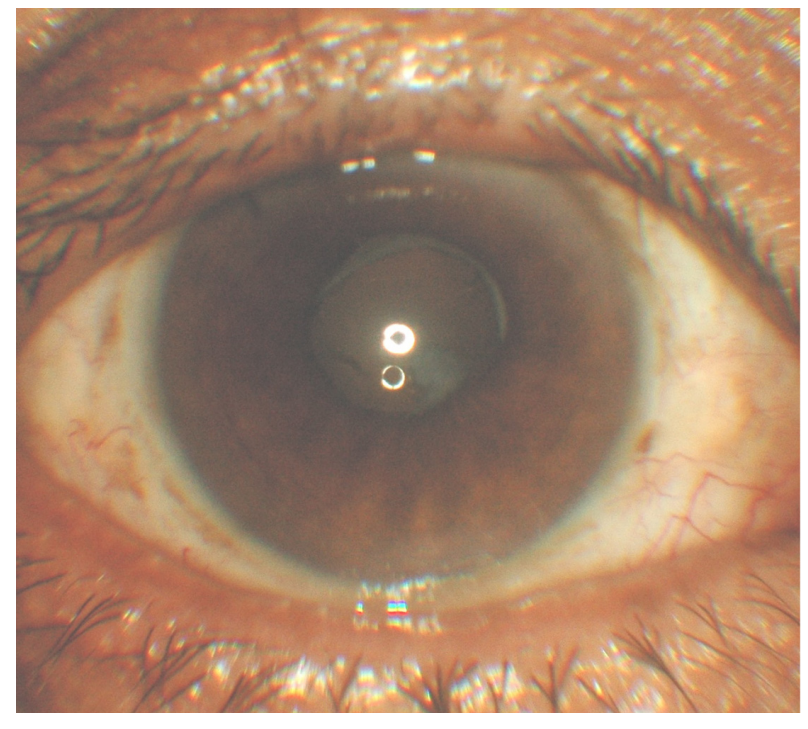

Figure 2 Anterior segment photograph showing a clear visual axis after laser anterior capsulotomy.

contraction of the anterior capsule following cataract surgery in patients with retinitis pigmentosa. ${ }^{7-11}$ The occurrence of anterior capsule contraction or phimosis has been reported, ranging from months to years after uneventful cataract surgery. ${ }^{7,8,10,11}$ It is alarming to note that our patient and Nikpoor and Stone's ${ }^{9}$ patient developed this similar problem less than a month following surgery.

It is presumed that the etiology of anterior capsule contraction in retinitis pigmentosa patients involves an imbalance between the centrifugal forces of the zonules and the forces of the intraocular lens haptics, and the centripetal forces of the proliferative and metaplastic residual lens epithelial cells. ${ }^{12}$ The anterior cuboidal lens epithelial cells undergo metaplasia with myofibroblastic transformation. These altered cells contain smooth-muscle actin and contraction results in fibrous membrane formation.

Our patient developed the anterior capsule contraction 2 weeks after surgery, and was treated with anterior Nd:YAG capsulotomy. He showed a satisfactory visual acuity in the affected eye after the treatment. We postulate that a relatively smaller capsulorhexis facilitated the anterior capsule contraction in the affected eye.

The occurrence of rapid anterior capsule opacification in his right eye had warned us regarding the possibility of a similar problem occurring in the contralateral eye. Early anticipation and relevant preventive measures were therefore our main concern before proceeding with surgery in the contralateral eye.

Interestingly, Nikpoor and Stone reported a fairly similar presentation to our case. ${ }^{9}$ They described a 43 -year-old man 
with retinitis pigmentosa who suffered from rapid anterior capsular contraction in each eye within 3 weeks following an uncomplicated phacoemulsification with continuous curvilinear capsulorhexis and a single-piece acrylic intraocular lens implantation. ${ }^{9}$ The anterior YAG capsulotomy was successfully performed in both eyes of their patient.

Both our patient and Nikpoor and Stone's patient did not display signs of intraocular lens instability. This suggests that early diagnosis of this condition is extremely important. We postulate that the severity and chronicity of this condition can lead to decentration, subluxation, and even spontaneous dislocation of the intraocular lens, as described by other authors. $^{7,8,10,11}$

Larger capsulorhexis size, ${ }^{7,13-15}$ use of a capsular tension ring, ${ }^{16,17}$ proper selection of intraocular lens, ${ }^{18,19}$ careful capsular lens epithelial cell clean-up, ${ }^{20-22}$ and radial relaxing incisions in the anterior lens capsule ${ }^{9,23,24}$ have all been advocated as effective measures to prevent or limit the occurrence of anterior capsule contraction.

The CT-Asphina 603P lens was implanted in our patient's right eye. The lens remained stable despite the development of a rapid anterior capsule opacification in the affected eye. In contrast, Lam and Visvaraja reported recently that five patients had spontaneous lens dislocations following uneventful phacoemulsification surgeries and CT-Asphina $603 \mathrm{P}$ posterior chamber lens implantation. ${ }^{25}$ However, their patients did not display significant capsular fibrosis.

We implanted an AcrySof IQ lens during subsequent surgery on the patient's left eye. The visual axis remained clear during his follow-up visits. A larger capsulorhexis and multiple radial incisions seemed helpful in preventing the occurrence of rapid anterior capsular contraction in this eye.

\section{Conclusion}

It remains a rare occurrence, but it is crucially important to highlight to ophthalmologists that anterior capsular contraction must be prevented in retinitis pigmentosa patients, as it may result in severe visual loss and problems with intraocular lens instability after cataract surgery.

\section{Disclosure}

The authors declare no conflicts of interest in this work.

\section{References}

1. Lee BL, Stenberg JP. Microscope light toxicity. Semin Ophthalmol. 1993;8(2):151-155.

2. Jackson H, Garway-Heath D, Rosen P, Bird AC, Tuft SJ. Outcome of cataract surgery in patients with retinitis pigmentosa. Br J Ophthalmol. 2001;85(8):936-938.
3. Cideciyan AV, Jacobson SG, Aleman TS, et al. In vivo dynamics of retinal injury and repair in the rhodopsin mutant dog model of human retinitis pigmentosa. Proc Natl Acad Sci U S A. 2005;102(14):5233-5238.

4. Takezawa M, Tetsuka S, Kakehashi A. Tangential vitreous traction: a possible mechanism of development of cystoid macular edema in retinitis pigmentosa. Clin Ophthalmol. 2011;5:245-248.

5. Fetkenhour CL, Choromokos E, Weinstein J, Shoch D. Cystoid macular edema in retinitis pigmentosa. Trans Sect Ophthalmol Am Acad Ophthalmol Otolaryngol. 1977;83(3 Pt 1):OP515-OP521.

6. Fishman GA, Maggiano JM, Fishman M. Foveal lesions seen in retinitis pigmentosa. Arch Ophthalmol. 1977;95(11):1993-1996.

7. Hayashi K, Hayashi H, Matsuo K, Nakao F, Hayashi F. Anterior capsule contraction and intraocular lens dislocation after implant surgery in eyes with retinitis pigmentosa. Ophthalmology. 1998;105(7):1239-1243.

8. Lee HJ, Min SH, Kim TY. Bilateral spontaneous dislocation of intraocular lenses within the capsular bag in a retinitis pigmentosa patient. Korean J Ophthalmol. 2004;18(1):52-57.

9. Nikpoor N, Stone DU. Rapid capsular phimosis in retinitis pigmentosa. Ophthalmic Surg Lasers Imaging. 2010;29:41.

10. Sudhir RR, Rao SK. Capsulorhexis phimosis in retinitis pigmentosa despite capsular tension ring implantation. J Cataract Refract Surg. 2001;27(10):1691-1694.

11. Najjar DM, Igbre AO, Tsai FF. Late capsular bag contraction and intraocular lens subluxation in retinitis pigmentosa: a case report. J Med Case Rep. 2011;5:65.

12. Davison JA. Capsule contraction syndrome. J Cataract Refract Surg. 1993;19(5):582-589.

13. Joo CK, Shin JA, Kim JH. Capsular opening contraction after continuous curvilinear capsulorhexis and intraocular lens implantation. J Cataract Refract Surg. 1996;22(5):585-590.

14. Taquri AH, Devlin H. Capsular phimosis following phacotrabeculectomy. Ophthalmic Surg Lasers Imaging. 2005;36(3):245-248.

15. Hayashi H, Hayashi K, Nakao F, Hayashi F. Anterior capsule contraction and intraocular lens dislocation in eyes with pseudoexfoliation syndrome. Br J Ophthalmol. 1998;82(12):1429-1432.

16. Tribus $C$, Alge CS, Haritoglou C, et al. Indications and clinical outcome of capsular tension ring (CTR) implantation: A review of 9528 cataract surgeries. Clin Ophthalmol. 2007;1(1):65-69.

17. Gimbel HV, Sun R. Role of capsular tension rings in preventing capsule contraction. J Cataract Refract Surg. 2000;26(6):791-792.

18. Zambarakji HJ, Rauz S, Reynolds A, Joshi N, Simcock PR, Kinnear PE. Capsulorhexis phymosis following uncomplicated phacoemulsification surgery. Eye (Lond). 1997;11(Pt 5):635-638.

19. Hayashi K, Hayashi H, Nakao F, Hayashi F. Anterior capsule contraction and intraocular lens decentration and tilt after hydrogel lens implantation. Br J Ophthalmol. 2001;85(11):1294-1297.

20. Tadros A, Bhatt UK, Abdul Karim MN, Zaheer A, Thomas PW. Removal of lens epithelial cells and the effect on capsulorhexis size. $J$ Cataract Refract Surg. 2005;31(8):1569-1574.

21. Sacu S, Menapace R, Wirtitsch M, Buehl W, Rainer G, Findl O. Effect of anterior capsule polishing on fibrotic capsule opacification: three-year results. J Cataract Refract Surg. 2004;30(11):2322-2327.

22. Hanson RJ, Rubinstein A, Sarangapani S, Benjamin L, Patel CK. Effect of lens epithelial cell aspiration on postoperative capsulorhexis contraction with the use of the AcrySof intraocular lens: randomized clinical trial. J Cataract Refract Surg. 2006;32(10):1621-1626.

23. Hayashi K, Yoshida M, Hirata A, Hayashi H. Anterior capsule relaxing incisions with neodymium:YAG laser for patients at high-risk for anterior capsule contraction. J Cataract Refract Surg. 2011;37(1):97-103.

24. Zhang ZD, Song Z, Chen D, Huang F. Bilateral capsule contraction syndrome following pathological myopic cataract surgeries. Int $J$ Ophthalmol. 2012;5(3):406-408.

25. Lam HH, Visvaraja S. Spontaneous dislocation of intraocular lens as a late complication of uncomplicated cataract surgery: a case series. Clin Exp Optom. 2012;95(1):99-102. 


\section{Publish your work in this journal}

Clinical Ophthalmology is an international, peer-reviewed journal covering all subspecialties within ophthalmology. Key topics include: Optometry; Visual science; Pharmacology and drug therapy in eye diseases; Basic Sciences; Primary and Secondary eye care; Patient Safety and Quality of Care Improvements. This journal is indexed on

Submit your manuscript here: http://www.dovepress.com/clinical-ophthalmology-journal
PubMed Central and CAS, and is the official journal of The Society of Clinical Ophthalmology (SCO). The manuscript management system is completely online and includes a very quick and fair peer-review system, which is all easy to use. Visit http://www.dovepress.com/ testimonials.php to read real quotes from published authors. 